\title{
MEDICINE
}

\section{COMBINATION OF TETRALOGY OF FALLOT AND HEMOPHILIA IN A CHILD: CASE REPORT}

\author{
Dr. Kulikova D. O. ${ }^{1}$, Dr. Pisklova Y. V. ${ }^{I}$, PhD Buchnieva O. V. ${ }^{1}$, PhD Piddubna I. M. ${ }^{2}$ \\ ${ }^{I}$ ST "Zaycev V.T. Institute of General and Urgent Surgery AMS of Ukraine”, Kharkiv. \\ ${ }^{2}$ Department of Pediatrics №2, Kharkiv National Medical University, Ukraine
}

DOI: https://doi.org/10.31435/rsglobal_ws/31072019/6588

\section{ARTICLE INFO}

Received: 25 May 2019

Accepted: 19 July 2019

Published: 31 July 2019

\section{KEYWORDS}

congenital heart disease,

tetralogy of Fallot,

hemophilia A,

surgical treatment,

coagulopathy.

\begin{abstract}
Congenital heart disease (CHD) is formed during intrauterine period but, as a rule, they are not hereditary. Hemophilia A belongs to the group of hereditary coagulopathies stipulated by deficiency of coagulation factor VIII and characterized by bleeding of hematoma like type. Combination of these two diseases is rather rare that requires cardiosurgeons' apprehensive attitude.

We present our experience in surgical treatment of a boy of 8 months old with Tetralogy of Fallot. Hemophilia A was found in preoperative examination. He was successfully operated with cardiac pulmonary bypass on the background of factor VII injection.

Surgical treatment was successful without significant bleeding. Postoperative period was uneventful. For successful treatment of CHD with coagulation failure is very important timely diagnosis, that can be difficult due to the lack of specific symptoms in children.

Surgical treatment is the method of choice in TOF. Timely and complete diagnosis of comorbidities allows to make it safe even in case of Hemophilia A.
\end{abstract}

Citation: Kulikova D. O., Pisklova Y. V., Buchnieva O. V., Piddubna I. M. (2019) Combination of Tetralogy of Fallot and Hemophilia in a Child: Case Report. World Science. 7(47), Vol.1. doi: 10.31435/rsglobal_ws/31072019/6588

Copyright: (C) 2019 Kulikova D. O., Pisklova Y. V., Buchnieva O. V., Piddubna I. M. This is an openaccess article distributed under the terms of the Creative Commons Attribution License (CC BY). The use, distribution or reproduction in other forums is permitted, provided the original author(s) or licensor are credited and that the original publication in this journal is cited, in accordance with accepted academic practice. No use, distribution or reproduction is permitted which does not comply with these terms.

Introduction. Congenital heart disease (CHD) is formed during intrauterine period but, as a rule, they are not hereditary. Hemophilia A belongs to the group of hereditary coagulopathies stipulated by deficiency of coagulation factor VIII and characterized by bleeding of hematoma like type. Genes stipulating development of hemophilia are X-linked; due to it the disease runs in the family by recessive inheritance through female lineage. Combination of these two diseases is rather rare that requires cardiosurgeons' apprehensive attitude [1].

Tetralogy of Fallot (TOF) is the complex anatomical anomaly of the heart stipulated by undevelopment of the right ventricle infundibulum. There are four components of this malformation in the typical case: stenosis of pulmonary artery, non-restrictive ventricular septum defect (VSD), dextraposition of the aorta and hypertrophy of the right ventricle. Perimembraneous VSD is detected in great majority of the patients but subaortal or supracristal localization of the defect is possible. TOF may be combined with other cardiac malformations: right sided arch of the aorta (20-25\%), vascular ring, secondary atrial septal defect (ASD), patent ductus ateriosus (PDA), patent common atrioventricular canal, persistent left superior vena cava, and partial drainage of pulmonary veins. Presence of the second muscular VSD is possible in 3-4\% cases. Combination of cardiac malformations and hemophilia is reported in literature $[5,7]$. 
Aim. To review our experience of the surgical treatment of child with TOF and Hemophilia A, the importance of timely and detailed diagnostics for the optimization surgical and therapeutic approach.

Material and Methods. Retrospective analysis of clinical case of combination of TOF and Hemophilia Ain a child operated in ST "Zaycev V.T. Institute of General and Urgent Surgery AMS of Ukraine".

Clinical case. A boy of 8 months old was admitted to the department of cardiosurgery and emergency cardiology from the regional cardiologic center of Kharkov regional clinical children's hospital with the diagnosis: Congenital heart disease, TOF. On admission parents complained of perioral cyanosis during agitation and appearance of dense subcutaneous masses with small ecchymoses on their surface. Congenital heart disease was diagnosed immediately after birth. The child stays under supervision of cardiologist.

Anamnesis vitae: The child is from $4^{\text {th }}$ normal pregnancy, $2^{\text {nd }}$ physiological delivery; gestational age was 39 weeks. He was not vaccinated. On the $1^{\text {st }}$ month the child was hospitalized to the municipal perinatal center with the diagnosis: Congenital heart disease, TOF, perinatal affection of CNS, syndrome of increased irritability, syndrome of dystonia, conjugative jaundice, protracted course.

Objective status on admission: child's condition was moderate concerning main and accessory diseases. He was conscious. Psychomotor development corresponded to age. Skin and mucous membranes were of usual color; single ecchymoses of $0.4 \mathrm{~cm}$ in diameter localized above subcutaneous induration were present on the right shank and on the anterior surface of the chest. The same ecchymoses used to appear during child's staying at a hospital. On percussion pulmonary sound was heard above lungs, on auscultation rough respiration was heard. Borders of relative heart dullness were enlarged $1.0 \mathrm{~cm}$ to the right. On palpation systolic thrill was detected in II-III intercostal spaces near the sternum border. On auscultation cardiac tones were rhythmic; rough systolic murmur was heard in all points of auscultation. Second tone above pulmonary artery was weak. CR was $124 \mathrm{bpm}$, $\mathrm{BP}$ was $85 / 50 \mathrm{~mm} \mathrm{Hg}, \mathrm{SpO} 2-96 \%$. The abdomen was soft, palpable in all regions. Liver's edge was $2 \mathrm{~cm}$ below the ribs arch; spleen was impalpable. Bowel and bladder functions were within normal.

$\mathrm{X}$-ray of the chest. Increased transparency of pulmonary pattern was detected. The heart in the frontal view had typical shape of "coeur en sabot". Second arch along left contour was markedly smoothed. Length of the heart was slightly increased, the apex is rounded, "blunt", lifted upwards and localized high above diaphragm.

ECG. Right axis deviation, high and sharpened wave $\mathrm{P}$, and signs of right ventricle hypertrophy were detected.

Echo-CG. VSD with left to right shunt with minimal gradient on the defect of $1.2 \mathrm{~cm}$ in diameter is detected. Dextraposition of aorta is $50 \%$. Moderate infundibular stenosis of pulmonary artery with gradient $32 \mathrm{~mm} \mathrm{Hg}$ is present. PDA is functioning.

EDD $-2.8 \mathrm{~cm}$, ESD $-1.7 \mathrm{~cm}, \mathrm{RV}-1.7 \mathrm{~cm}, \mathrm{RA}-1.9 \mathrm{~cm}, \mathrm{LA}-2.4 \mathrm{~cm}$. Blood flow in abdominal aorta is of pulsatile character. Arch of aorta is localized typically. Valves are unremarkable.

The child was examined in hematological department of Kharkov Municipal Clinical Children's Hospital №16. Common blood count was unremarkable. Blood clotting time: beginning at 5'20", end at 5'47'. Duration of bleeding - 1'39'. Functional liver test: ALT - $1.1 \mathrm{mmol} / \mathrm{l}$, ALP - $3.9 \mathrm{U}$, thymol test $2.5 \mathrm{U}$, total bilirubin $-20.9 \mu \mathrm{mol} / \mathrm{l}$, direct bilirubin $-5.9 \mu \mathrm{mol} / 1$, indirect bilirubin $-15.0 \mu \mathrm{mol} / 1$.

Proteinogram: total protein $-64 \mathrm{~g} / \mathrm{l}$, albumin $-71.5 \%$, globulins: $\alpha_{1}-2.8 \%, \alpha_{2}-8.3 \%, \beta-$ $7.0 \%, \gamma-10.4 \%$.

Autocoagulation test: A $<1 \%, \mathrm{~T} 1-12 \mathrm{~min}, \mathrm{~T} 2-20 \mathrm{~min}, \mathrm{MA}-85 \%, \mathrm{~F}-50$, inactivation index of thromboplastin -2.4 , fibrinogen $-2.2 \mathrm{~g} / \mathrm{l}$, prothrombin time $-83 \%$.

Activity of factor VIII- $0.0 \%$, activity of factor IX $-27.5 \%$.

The following diagnosis was made: Hemophilia A, severe form.

Taking into account indications for operation, complete support with blood preparations according to hematologists recommendations, it was decided to operate the child under cardiopulmonary bypass.

Plastics of the defect of ventricular septum with baffle patch Gore-tex, PDA ligation, excision of infundibular stenosis on the background of factor VII injection at the rate of $50 \mathrm{U} / \mathrm{kg}$ every 8 hours as preoperative preparation during 3 days and during 6 days after operation.

Results. Surgical treatment was successful without significant bleeding. Postoperative course was unremarkable. The child was discharged from the hospital on the $10^{\text {th }}$ day after operation in satisfactory condition under supervision of cardiologist and hematologist. 
Discussion. Congenital heart disease is formed during intrauterine period but, as a rule, they are not hereditary. According to medical statistics, probability of congenital heart disease development as related to total population is 1:100 healthy children. TOF is one of the most wide spread cyanotic congenital heart disease [6]. It is diagnosed in 10-30\% of infants suffering from congenital heart disease. French pathologist Fallot described this pathology as nosological entity for the first time in 1888 year. Pathological manifestations vary because each of the anatomical signs can have different form and intensity. Absence of cyanosis in this child can be explained by functioning of PDA via which blood passed from aorta to lungs and compensated lack of blood flow of lesser circulation. Treatment of this pathology is surgical. Specific prophylaxis is not worked out.

Hemophilia A is a disease from the group of hereditary coagulopathies stipulated by deficiency of coagulation factor VIII and characterized by bleeding of hematoma like type. Genes stipulating development of hemophilia are X-linked; due to it the disease runs in the family by recessive inheritance through female lineage. Hemophilia can manifest in whatever age. Disease manifests with bleeding of various localization, appearance of painful intermuscular hematomas and hemarthroses.

Decreased consumption of prothrombin, delayed recalcification time, delayed blood clotting time (capillary and venous), decreased quantity of factor VIII, and disorders of thromboplastin formation are detected in laboratory tests. Replacement therapy is the main principle of hemophilia's treatment. Nowadays is it performed with the help of intravenous infusions of concentrated preparations of factor VIII which allow achieving hemostatic factor's level [8].

Calculation of the dose of concentrated factor VIII:

Dose $(\mathrm{IU})=$ body weight $\mathrm{x}$ (required activity - basal activity).

Presently purified factors are used in which both enveloped (HIV, viruses of hepatitis B and C), and non-enveloped (virus of hepatitis A, parvovirus) viruses are extracted. Methods of genetic treatment are under development [3]. Coagulation factors VIIa (NovoSeven) and VIII (Kogenate) are successfully used. Possibility of getting of transgenic cow's milk enriched with factor VIII is reported [4].

Genetic counselling of marrying persons is the most important measure. Rather often families having a child suffering from hemophilia are in need of comprehensive assistance for resolving problems of the whole family [8].

On retrospective investigation of frequency of hemophilia and congenital heart pathology combination, as well as X-linked diseases, one case of CHD upon 134 patients with hemophilia was found, giving frequency $0.75 \%$ in comparison with $0.8 \%$ in general population at birth. In this research significant difference in frequency of combination of CHD with hemophilia A and B in comparison with data in general population or significant difference between relatives of patients suffering from hemophilia in comparison with control group has not been found [2].

Conclusions. Surgical treatment has been and remains the method of choice in TOF. The closest and long-term prognosis for patients operated with TOF are usually favorable. Timely and complete diagnosis of comorbidities and specific preparation for the intervention allows to perform surgery safely even in case of Hemophilia A.

\section{REFERENCES}

1. Consensus Review of the Treatment of Cardiovascular Disease in People with Hemophilia A and B / V.A. Ferraris, L.I. Boral, A.J. Cohen [et al.] // Cardio Rev. - 2015. - Vol. 23 (2). - P. 53-68.

2. Frequency of congenital heart defects in patient with hemophilia / Jedele K.B., Michels V.V., Gordon H., Gilchrist G.S. // Am J Med Genet. - 1990. - Vol. 36 (3). - P. 333-335.

3. Murphy S.L. Gene therapy for haemophilia / Samuel L. Murphy, Katherine A. High // Br J Haematol. 2008. - Vol.140. - P. 479-487.

4. Patent EP 0502976 A1. Production of recombinant polypeptides by bovine species and transgenic methods / H.L. Heyneken, H.A. Deboer, R. Strijker, G. Plantenburg, S.H. Lee. Applicant: Genfarm Int., US; filling 30/11/1990; publ. 16/09/1992. - 4 p.

5. Pulmonary valve stenosis and haemophilia A. / Zvi Ackerman, G. Koren, M. Gotsman [et al.] // Arch Intern Med. - 1986. - Vol. 146 (11). - P. 2233-2234.

6. Territo M.C. Cyanotic Congenital heart disease: Hematologic management / M.C. Territo, M.H. Rosove // JACC. - 1991. - Vol. 18 (2). - P. 320-323.

7. Tetralogy of Fallot and haemophilia A: successful management of intracardiac repair / E. Rupert, K. Muralidhar, D.P. Shetty // Asian Cardiovasc Thorac Ann. - 1999. - Vol. 7. - P. 132-134.

8. The past and future of haemophilia: diagnosis, treatments, and its complications / F. Peyvandi, I. Garagiola, G. Young // The Lancet. - 2016. - Vol. 388. - P. 187-197. 